\title{
Mind-Brain Dichotomy, Mental Disorder, and Theory of Mind
}

DOI:

10.1007/s10670-018-0038-0

\section{Document Version}

Accepted author manuscript

Link to publication record in Manchester Research Explorer

\section{Citation for published version (APA):}

Buckwalter, W. (2018). Mind-Brain Dichotomy, Mental Disorder, and Theory of Mind. Erkenntnis.

https://doi.org/10.1007/s10670-018-0038-0

\section{Published in:}

Erkenntnis

\section{Citing this paper}

Please note that where the full-text provided on Manchester Research Explorer is the Author Accepted Manuscript or Proof version this may differ from the final Published version. If citing, it is advised that you check and use the publisher's definitive version.

\section{General rights}

Copyright and moral rights for the publications made accessible in the Research Explorer are retained by the authors and/or other copyright owners and it is a condition of accessing publications that users recognise and abide by the legal requirements associated with these rights.

\section{Takedown policy}

If you believe that this document breaches copyright please refer to the University of Manchester's Takedown Procedures [http://man.ac.uk/04Y6Bo] or contact uml.scholarlycommunications@manchester.ac.uk providing relevant details, so we can investigate your claim.

\section{OPEN ACCESS}




\title{
Mind-Brain Dichotomy, Mental Disorder, and Theory of Mind* \\ Wesley Buckwalter \\ wesleybuckwalter@gmail.com
}

\begin{abstract}
The tendency to draw mind-brain dichotomies and evaluate mental disorders dualistically arises in both laypeople and mental health professionals, leads to biased judgments, and contributes to mental health stigmatization. This paper offers a theory identifying an underlying source of these evaluations in social practice. According to this theory, dualistic evaluations are rooted in two mechanisms by which we represent and evaluate the beliefs of others in folk psychology and theory of mind: the doxastic conception of mental disorders and doxastic voluntarism. Tracing these origins contributes to our understanding of mental state representation in cognitive science and philosophy of psychiatry, the concept of belief in philosophy of mind, and may help improve patient experience and treatment in light of social stigmatization and bias toward mental illness.
\end{abstract}

Keywords: mental disorder; dualism; folk psychology; belief; voluntarism; responsibility

\footnotetext{
${ }^{*}$ This article will appear in Erkenntnis. Please cite the published version.
} 
Sickness is a hindrance to the body, but not to your ability to choose, unless that is your choice... say this to yourself with regard to everything that happens, then you will see such obstacles as hindrances to something else but not to yourself. - Epictetus

\section{Introduction}

Despite the ubiquity and seriousness of mental illness as a growing public health concern, misconceptions and biases toward mental illness remain widespread in society (Lim, Jacobs, and Dewa 2008; Smetanin et al. 2011). For example, it is sometimes thought that mental illnesses are the result of "personal weakness," lack of "self-control," or serve as excuses for unacceptable behavior (Byrne 2001; Crandall and Moriarty 1995; Hinshaw and Stier 2008; Weiner, Perry, and Magnusson 1988). These conceptions can differentially impact the way mental disorders are perceived, delay their reporting and treatment, and reduce the quality of life for those directly or indirectly suffering from mental illness. There is a critical need to understand the philosophical and psychological underpinnings of mental health stigmatization and bias in order to begin to alleviate these negative outcomes.

Such conceptions about mental disorders are thought to stem from the enormously influential and centuries-old philosophical theory that the mind is separate from the body (Kendler 2001, 2005; Leitan and Murray 2014). In psychiatry, this appears to have manifested itself in the form of substance dualism, or the belief that mental and physical processes are made of fundamentally different kinds of things (Kendler 2005: 434). If the mind is made of distinct components from the brain or biological body, it might be 
thought, then this suggests that illnesses of the mind should be treated essentially different from illnesses of the physical body. This, in turn, explains why mental disorders are perceived and treated differently than the vast majority of bodily afflictions and can encourage further misconceptions about them to persist.

Researchers in philosophy, psychology, and psychiatry have begun to document the prevalence of dualistic evaluations of mental disorder and the effects this can have on psychiatric diagnosis and treatment (Kendler 2005; Raese 2014). For the purposes of this paper, "dualist evaluations" will refer to the tendency to perceive of mental disorders, their associated components, or their effects, significantly differently from physical disorders. This research suggests that both laypeople and highly trained professionals persistently conceive of mental disorders dualistically and that this can contribute to negative outcomes, such as feelings of guilt and blame regarding mental illness and treatment compared to other illnesses (Buckwalter and Turri 2015; Crandall and Moriarty 1995; Miresco and Kirmayer 2006; Weiner, Perry, and Magnusson 1988). However, the origins and continued persistence of dualistic evaluations in social cognition underlying lay and professional judgments is not fully understood. Understanding why we are so inclined to assess mental disorders in this way is essential for improving the treatment of mental illness and overcoming biases associated with them.

This paper offers a theory identifying an underlying source of dualistic evaluations of mental disorders. According to this theory, the tendency to evaluate mental disorders dualistically is deeply rooted in folk psychology and the mechanisms by which we represent and evaluate the beliefs of others in theory of mind. Specifically, it is hypothesized that two features of this system underlie dualistic appraisals of mental 
disorders in social practice: the doxastic conception of mental disorders, or the view that contents of certain mental disorders are beliefs, and doxastic voluntarism, or the view that we have the same sort of willful control over our beliefs that we have over our actions. The remainder of this paper reviews recent research in experimental cognitive science demonstrating that these features accurately capture mental state representations of belief in social cognition and argues that such judgments may explain the continued tendency to evaluate disorders dualistically in lay and clinical practice. The paper concludes with a discussion of how understanding these origins may begin to help overcome dualistic appraisals and reduce social stigmatization and bias toward mental illness.

\section{Dualistic Appraisal in Clinical and Lay Practices}

One broad philosophical approach to psychiatric science, often referred to as the "scientific" or "biological" approach, views the mind as a physical entity that is entirely dependent on brain functioning. A different approach, often referred to as the "dualistic" approach in psychiatry, views the mind as a disembodied entity that is somehow distinct from the brain or other physical systems. According to the dualistic approach, mental disorders are not brain or neurological disorders and thus should be treated somehow differently than other biological pathologies.

Researchers across a diverse range of fields in philosophy, cognitive science, and medicine have rejected this broad dualist approach. In recent years, psychiatrists have also come to reject theories positing mind-brain dichotomies as incorrect and potentially

harmful accounts of mental disorders (Kendler 2005). But despite calls for rejecting 
mind-brain dichotomies within the field (Andreasen 1997; Gabbard 2005; Kandel 1998), dualistic approaches still implicitly inform various aspects of psychiatric training, practice, and treatment (Kirmayer 1988; Luhrmann 2000; Miresco and Kirmayer 2006). This growing body of research suggests that dualistic appraisals influence the evaluation and treatment of mental disorders in a variety of contexts. For instance, one recent attempt to track these effects has demonstrated that professional psychiatrists and psychologists appeal to mind-brain dichotomies when explicitly evaluating individual clinical scenarios (Miresco and Kirmayer 2006). This research has shown that professionals tend to reason dualistically about patient symptoms and that this correlates with judgments about moral responsibility and blameworthiness concerning mental health.

In Miresco \& Kirmayer's study, for example, clinicians and researchers in the psychiatry department at McGill University were asked to evaluate a series of hypothetical clinical vignettes. Each of the vignettes featured a patient suffering from one of three common psychiatric conditions. These conditions were selected based on the degree to which they are generally thought to be either "neurobiologically" or "psychologically" determined. In one vignette, for instance, the patient suffered a manic episode that was chemically induced, which is generally seen as a "biological" condition. Another vignette featured a patient suffering from narcissistic personality disorder, which is typically perceived as a "psychological" condition. The third group of cases featured a patient suffering from heroin addiction, which is typically perceived somewhere in between a purely "biological" and a "psychological" condition. Patients described in these vignettes then went on to engage in one of three behaviors: spending money to the 
point of bankruptcy, contracting HIV by engaging in unsafe sexual practices, or murdering a spouse. This resulted in nine combinations of cases that manipulated both the perceived etiology of the condition, and the behaviors that the patients went on to engage in as a result.

Participants were then asked a series of questions about the cases they saw. Among other things, participants were asked how blameworthy the patient was (e.g., "How much is Dave to blame for going bankrupt?"), whether the patient acted intentionally, was in control, and whether the patient should be held responsible for their behavior. These judgments were combined to create a joint measure designed to gauge the responsibility of the patient for engaging in the bad behavior. Participants were also asked to indicate how important they thought neurobiological and psychological factors were in explaining the bad outcomes of the behaviors (e.g. "How important are neurobiological/psychological factors in explaining why Dave went bankrupt?”).

Researchers found that responsibility judgments were positively correlated with judgments that the behaviors were the result of psychological factors, and negatively correlated with judgments that they were the result of biological factors. In other words, patients displaying symptoms seen as more "psychologically" determined (e.g. the personality disorder) were regarded as more blameworthy, in greater control of, and responsible for their behaviors than when symptoms were seen as "biologically" determined (e.g. the mood disorder, and to a lesser extent, the drug addiction).

Three additional aspects of this study are noteworthy. First, Miresco \& Kirmayer's findings were not affected by training in pharmacotherapy, psychotherapy or psychoanalysis. Neither specialization in research nor clinical practice seemed to deter 
participants from utilizing mind-brain dichotomies when evaluating moral responsibility. Second, mental health professionals are well aware that personality disorders are very difficult to treat precisely because their effects and associated behaviors are often irresponsive to direct, conscious control. Nonetheless these participants still attributed high degrees of responsibility to patients with these conditions. Lastly, this effect on professional appraisals persisted even though over a third of the participants correctly guessed the research hypothesis of the study prior to completing the experiment. Because of this, one might have expected responsibility judgments to decrease, but this did not happen. Foreknowledge of the hypothesis had no detectable effect on these judgments. These facts suggest that mind-brain dichotomies have a powerful and disquieting effect on evaluations of mental health cases among highly trained individuals.

The mind-brain dichotomies drawn by mental health professionals and their effect on moral judgment in Miresco \& Kirmayer's study are consistent with the results of studies of lay-judgments made by ordinary adults in the general population (Buckwalter and Turri 2015; Crandall and Moriarty 1995). For instance, recent studies among lay populations have revealed that psychologically incapable agents are more likely to be judged "literally able" to fulfill obligations, and more likely to be blamed for failing to fulfill those obligations, than their counterparts with analogous physical inabilities. In one experiment, for example, researchers presented participants with one of two stories featuring an agent who fails to fulfill a promise (Buckwalter and Turri 2015: Experiment 1). The cases differed only in whether the reason for the agent's failure was described in physical or psychological terms: 
Walter promised that he would pick up Brown from the airport. But on the day of Brown's flight, Walter is [in a serious car accident/suffering from clinical depression]. As a result, Walter is not [physically/psychologically] able to pick up Brown at the airport.

After seeing one of these two cases, participants were asked about Walter's abilities (e.g. "Walter is literally unable to pick up Brown at the airport") and blameworthiness (e.g. "Walter deserves to be blamed for the fact that Brown was not picked up."). Researchers found that participants were consistently more likely to answer that agents "literally" do have the ability to fulfill their obligations, and are much more blameworthy for failing to fulfill those obligations, when the reasons for failure were described psychologically rather than physiologically. In other words, psychologically incapable agents, in this case, sufferers of clinical depression, were much more likely to be judged "literally able" to fulfill basic obligations. They were also considered much more blameworthy for failing to fulfill their obligations than agents with comparable physical afflictions (e.g. physical injury).

Three additional aspects of these findings are also noteworthy. First, it is striking that mind-brain dichotomies impacted lay judgments to such a degree that they did even though minimal details of the conditions were provided. For example, participants were not given any details about the circumstances of Walter's car accident or the extent of the injuries he received. Nonetheless this tiny manipulation led to large differences in blame and ability judgments compared to when clinical depression was mentioned. Second, these results have been replicated across a number of different cover stories involving different kinds of afflictions and moral obligations. For instance, similar patterns of 
judgments also emerged in cases involving anxiety disorders (Buckwalter and Turri 2015: Experiment 2). Lastly, this effect was extremely large. In the case above, for instance, researchers found that the odds that the agent was judged "literally unable" to act increased by a factor of 95 simply by changing the type of inability mentioned in the story from psychological to physical.

These findings illustrate the ways that dualistic thinking about mental disorders can impact judgments about mental health. More specifically, dualistic thinking about mental disorders can radically impact judgments concerning ability, control and moral responsibility of behaviors associated with mental disorder compared to physical disorder. Such effects persist among lay-people and highly trained health professionals. Highly trained professionals even make such judgments when explicitly acknowledging their existence during psychological testing. These facts and the persistence of such judgments have led some researchers to conclude that dualistic appraisals of mental disorder "reflects a basic cognitive schema", one that is used "intuitively to understand human behavior" (Miresco and Kirmayer 2006: 913). But several questions about the source of these appraisals remain. What is this basic cognitive schema, and how does it perpetuate mind-brain dichotomies and subsequent judgments implicated in reactions to physical and mental disorders?

\section{Doxastic Conception of Mental Disorders}

Folk psychology is a basic cognitive schema that we use to intuitively understand the minds of others. Specifically, it is the fundamental capacity we have to represent, predict, and explain mental states and subsequent behaviors. Belief is a central plank of folk 
psychology. Detecting when others have beliefs is an essential aspect of successful social cognition, cooperation, and communication (Baron-Cohen 1996; Bartsch and Wellman 1995; Malle 2003; Perner 1991; Wellman 1990). Given the centrality of belief in folk psychology and everyday judgment, this system for detecting beliefs and explaining behavior is a good place to begin to explore persistent dualistic appraisals associated with mental disorders.

One powerful cue for belief representation is frequent assertion. All else equal, a person who willingly asserts a claim seems more likely to believe that claim than a person who is not willing to assert it. The same seems true for a person who continually asserts a claim over and over again compared to another person only willing to assert that claim once. These observations have recently been empirically confirmed through a series of studies examining the connection between belief and assertion in folk psychology (Rose, Buckwalter, and Turri 2014; Rose et al. 2017). This research has demonstrated that ordinary judgments about what others believe are highly sensitive to frequent assertion in these ways. In fact, frequent assertion can sometimes have a greater impact on belief representation than even a robust and consistent track record of nonverbal behavior can. In other words, and contrary to the old adage, when reasoning about the mental states of others, words can sometimes speak louder than actions.

Does the effect of frequent assertion on belief representation continue to persist even in pathological cases, when assertions and actions might significantly diverge? This question connects to a foundational debate in philosophy of psychiatry regarding delusional disorders and the stereotypical functional profile of belief. Specifically, this debate regards whether the contents of monothematic clinical delusions, such as Capgras 
or Fregoli delusion, for instance, should be classified as beliefs as opposed to some other kind of mental state. Monothematic delusions refer to delusions that have one particular topic, focus, or theme, in Capgras delusion, for example that someone you know has been replaced by an imposter, in Fregoli delusion, that different people are actually a single person in disguise.

A popular view in philosophy is that delusional attitudes resulting from these disorders are not beliefs because belief is thought to require behavioral integration and circumscription that is lacking in paradigmatic cases of delusion (for discussion, see Bayne 2010: 330; Egan 2009; Tumulty 2012). These philosophical theories concerning the nature of belief notwithstanding, it remains an open question whether folk psychology represents such states as beliefs in theory of mind, even when they conflict with other thoughts or behaviors (though, see Bortolotti and Mameli 2012).

Researchers have confirmed the effect of frequent assertion on belief representation in folk psychology in pathological cases involving mental disorders, and specifically, delusion (Rose, Buckwalter, and Turri 2014). Participants in these studies were asked to evaluate the beliefs of patients presenting with Capgras syndrome. Capgras syndrome is a delusional disorder in which patients mistake family members, loved ones and friends with imposters. On the one hand, patients suffering from this delusion typically do not engage in the behaviors one might expect given a belief that loved ones have been replaced by imposters. For example, Capgras patients typically continue to live together, do not run away, call the police or display violent outbursts of behavior against the presumed imposters (see, for example Hirstein and Ramachandran 1997). On the other hand, patients still continually assert that their loved ones have been replaced by 
imposters, even while acknowledging the objective implausibility of this claim. This raises the following question: do we still represent such patients as believing that imposters have replaced their loved ones?

What researchers discovered is that we do represent such delusions as beliefs. Using different dichotomous measures for probing belief attribution, researchers found in one study that over $90 \%$ of participants agreed that a patient suffering from Capgras syndrome believed that loved ones were replaced by an imposter (Rose, Buckwalter, and Turri 2014: Experiment 1). Other studies by these researchers replicated this finding using different techniques, such as using continuous measures to detect belief attribution, and by comparing judgments about belief to other closely related mental states such as "imagination". Belief was consistently ascribed to patients with delusional attitudes, suggesting that folk psychological judgments were much more attentive to verbal behaviors in this case (e.g. the patient's assertion that there was an imposter) rather than non-behaviors (e.g. the lack of other actions that might make sense given would-be imposters).

One experiment in particular strongly demonstrated the role of assertion in belief ascription in folk psychology (Rose, Buckwalter, and Turri 2014: Experiment 5). In it, participants were presented with one of four vignettes that manipulated two variables. The first variable was whether or not the case was pathological or non-pathological. The protagonist of the pathological vignette displayed symptoms typical of Fregoli delusion, while the non-pathological case simply featured a normal adult male. The second variable was the degree to which the protagonist asserted an unlikely claim. The cases read as follows, with manipulations in brackets below: 
Don works in a large office building. He also has a rare [passion for mystery novels/delusional psychiatric disorder] that can cause strange behaviour. For instance, one day, Don tells his boss, 'You look just like a normal citizen, but you're really a foreign spy, working on a secret mission.' [And/But] that [was/ was not] the only time Don said that. From then on, he [never said it again/ said it every day].

After reading one of these four cases participants were asked a series of questions including whether or not "Don believes that his boss is a spy".

The result was that the frequency of assertion played a powerful role in belief attribution concerning that assertion. Don was more likely to be represented as believing that his boss was a spy when he asserted that claim daily than when he only made that assertion one. Furthermore, frequent assertion had this effect on belief attribution in both pathological and non-pathological cases, and if anything, appeared to amplify belief attribution in pathological cases. These results are shown in Figure 1.

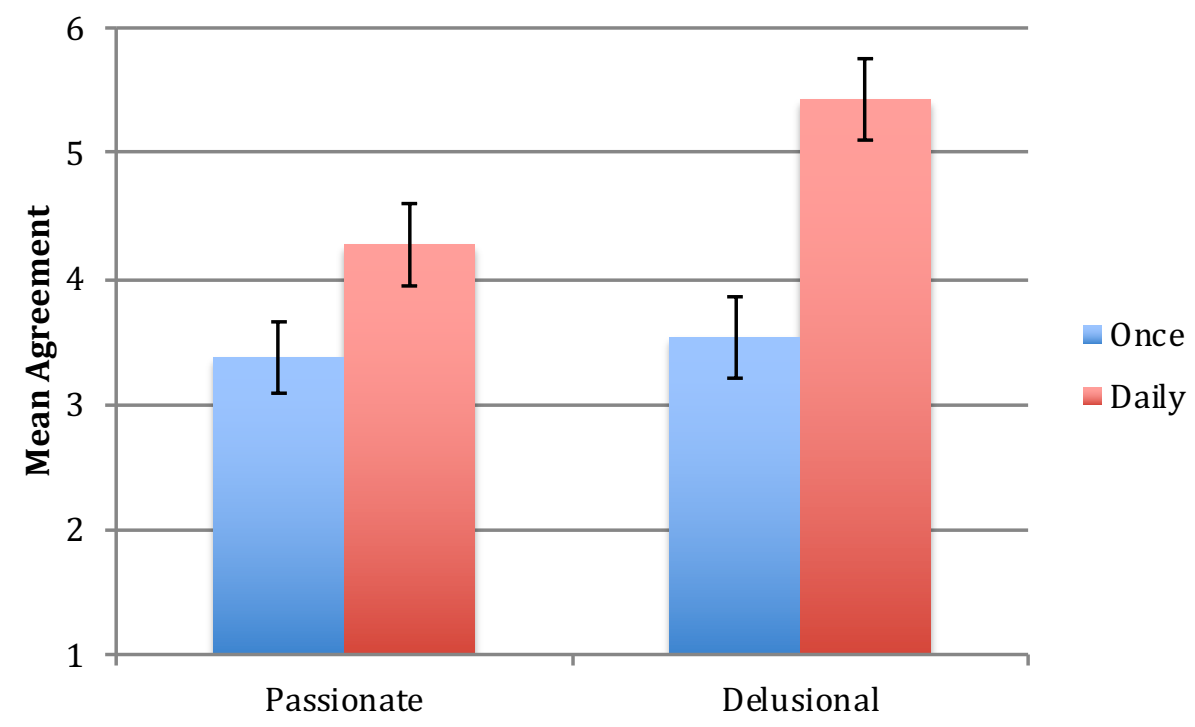


Fig. 1: Representation of results by Rose, Buckwalter, and Turri (2014: Experiment 5). Agreement ratings for belief in cases of infrequent and frequent assertion grouped by non-pathological cases and pathological cases. All scales ran from 1 to 7 . Error bars +/one standard error of the mean.

For present purposes, there are two important conclusions to be drawn from these findings. First, what people say about their own mental states plays a powerful role in our determinations about what they believe. Sometimes this plays an even greater role than a consistent track record of behavior does. Second, this feature of the folk psychological system is active in normal circumstances, as well as in pathological cases, such as when participants are asked to evaluate patient scenarios. What a patient says about their conditions can strongly influence our judgments about the things we think that patient believes.

\section{Doxastic Voluntarism}

Research on Capgras and Fregoli cases reveals that other things being equal, repeatedly asserting a proposition can suffice for representing and attributing belief in folk psychology. But repeatedly asserting something is a voluntary activity: we can choose to do so, directly, at will, and self-consciously so. If assertion is sometimes sufficient for belief representation, and assertion is a voluntary activity, then folk psychology might also acknowledge a clear sense in which belief is voluntary. In other words, these results appear to suggest that folk-voluntarism about belief is true (and indeed, an extremely strong version of voluntarism). 
Whether or not belief is voluntary or involuntary is a foundational debate in the philosophy of mind. Voluntarism is the thesis that we have the same sort of control over our beliefs that we have over our actions. Philosophers have historically been divided on this claim, with some throughout the history of philosophy endorsing versions of voluntarism (Descartes 1644/1985; James 1948) and others endorsing involuntarism (Hobbes 1641). Today, the majority of epistemologists and philosophers of mind hold that voluntarism about belief is false, either as an empirical matter of human physiology or as a matter of conceptual necessity concerning our concept of belief (Alston 1988; Bennett 1990; Williams 1973). Of course, it is possible that these theorists are correct about the true nature of belief regardless of whether beliefs are or are not represented as being held voluntarily or involuntarily in folk psychology and theory of mind. But until recently, at least, the latter question remained as to whether folk psychology embraces voluntary or involuntary belief.

Further empirical investigation into the matter revealed that folk psychology strongly countenances voluntary belief, and perhaps even views belief as the most voluntary propositional attitude (Turri, Rose, and Buckwalter 2017). Across several experiments, researchers discovered that belief attribution is strongly influenced by a protagonist's professed choice to believe or refuse to believe a proposition. Researchers also found that manipulating the strength of an agent's willpower significantly affects whether people agree that those agents hold a belief by choice or can choose to believe voluntarily. These effects persisted even after controlling for the level of evidence that the person had that the beliefs in question were true or false. Together, these effects 
suggest that folk psychology posits a strong connection between willful control and belief.

In one study, for instance, participants were probed about ten different mental states to assess whether some were viewed as more voluntary than others (Turri, Rose, and Buckwalter 2017: Experiment 1A). Each participant was presented with the same basic story involving the chief of staff to a governor of a large state. In each story, the governor tells the chief of staff that her administration will fully support the passage of House Bill H1998. She also says that anyone who wishes to continue as part of her administration must be in a certain mental state about the bill. The stories differed in the type of mental state she required staff members to have towards the bill passing: belief, knowledge, opinion, faith, support, want, intention, doubtlessness, excitement, and fearlessness (e.g. "believe that the bill will pass", "have no doubt that the bill will pass", etc.). In the conclusions of the stories, the chief of staff decides that because she wants to continue in the administration, she will choose to occupy the mental state that the governor identified. Participants were then asked a series of questions about these cases, including whether the chief of staff can choose to be in one of the ten mental states about the bill passing.

Researchers found that participants evaluated the voluntary nature of the mental states differently. For instance, participants were inclined to treat having a belief, having faith, or being fearless as more voluntary than states like knowledge or having no doubts. They also found that belief was considered a highly voluntary state, and in fact, that it was rated the most voluntary of the ten mental states included in the study. Specifically, 
participants strongly agreed that the chief of staff "could choose to believe that the bill will pass." These results are displayed in Figure 2.

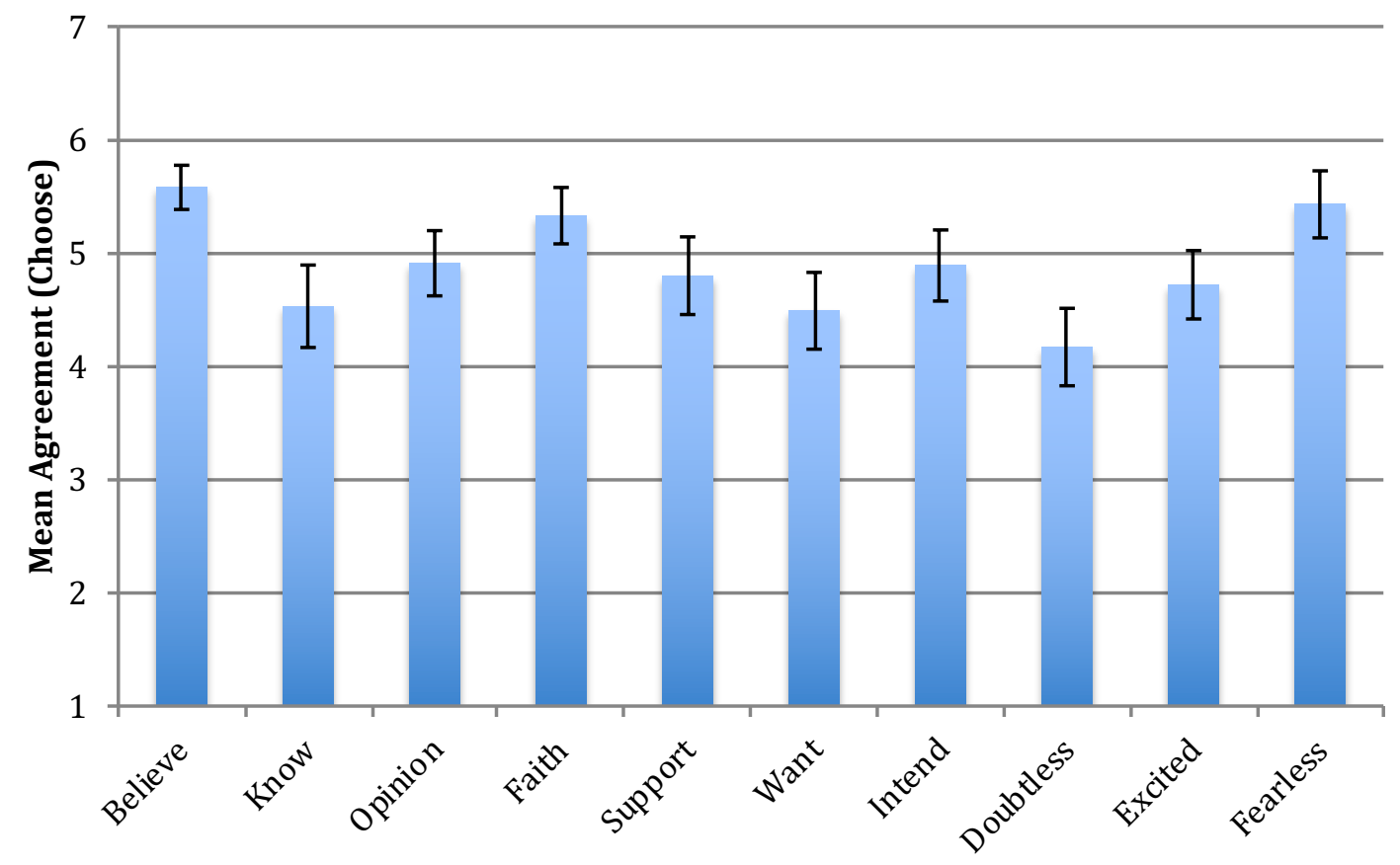

Fig. 2: From Turri, Rose, and Buckwalter (2017: Experiment 1A), mean agreement with the test statement that the protagonist can choose to be in the mental state. "All scales ran from 1 to 7. Error bars +/- one standard error of the mean." Reprinted with permission.

The results of this experiment suggest that folk psychology discriminately sorts mental states as being more or less voluntary. At the same time, however, many states were viewed as voluntary, especially and including belief. To explore this effect in greater detail, researchers also conducted intervention studies that measured the effect of willfulness and evidence on belief ascription in folk psychology. In one study, for instance, researchers presented participants with short vignettes manipulating the level of evidence that a protagonist had for a certain claim (Turri, Rose, and Buckwalter 2017: 
Experiment 3). Also manipulated, was whether the protagonists chose to believe a proposition or refused to believe it. This resulted in six vignettes indicated in brackets below:

Malcolm planned a graduation party for tomorrow at the local park. He checks the weather forecast and sees that there is a $[5 / 50 / 95] \%$ chance that it will rain tomorrow. Malcolm has a tendency to be very [optimistic/pessimistic]. He thinks to himself, "I [refuse/choose] to believe that it's going to rain tomorrow."

After participants read one of the six vignettes they were asked a series of questions, including whether or not "Malcolm believes that it will rain tomorrow."

Researchers found that belief attribution was strongly influenced by a protagonist's professed choice to believe or refuse to believe the proposition that it will rain tomorrow. When the protagonist chooses to believe it will rain, people overwhelmingly attributed belief. When the protagonist said that he refuses to believe it, they overwhelming denied belief. At the same time, it made little difference whether the protagonist's evidence indicated that the probability that it would rain was high or low. These findings are shown in Figure 3. 


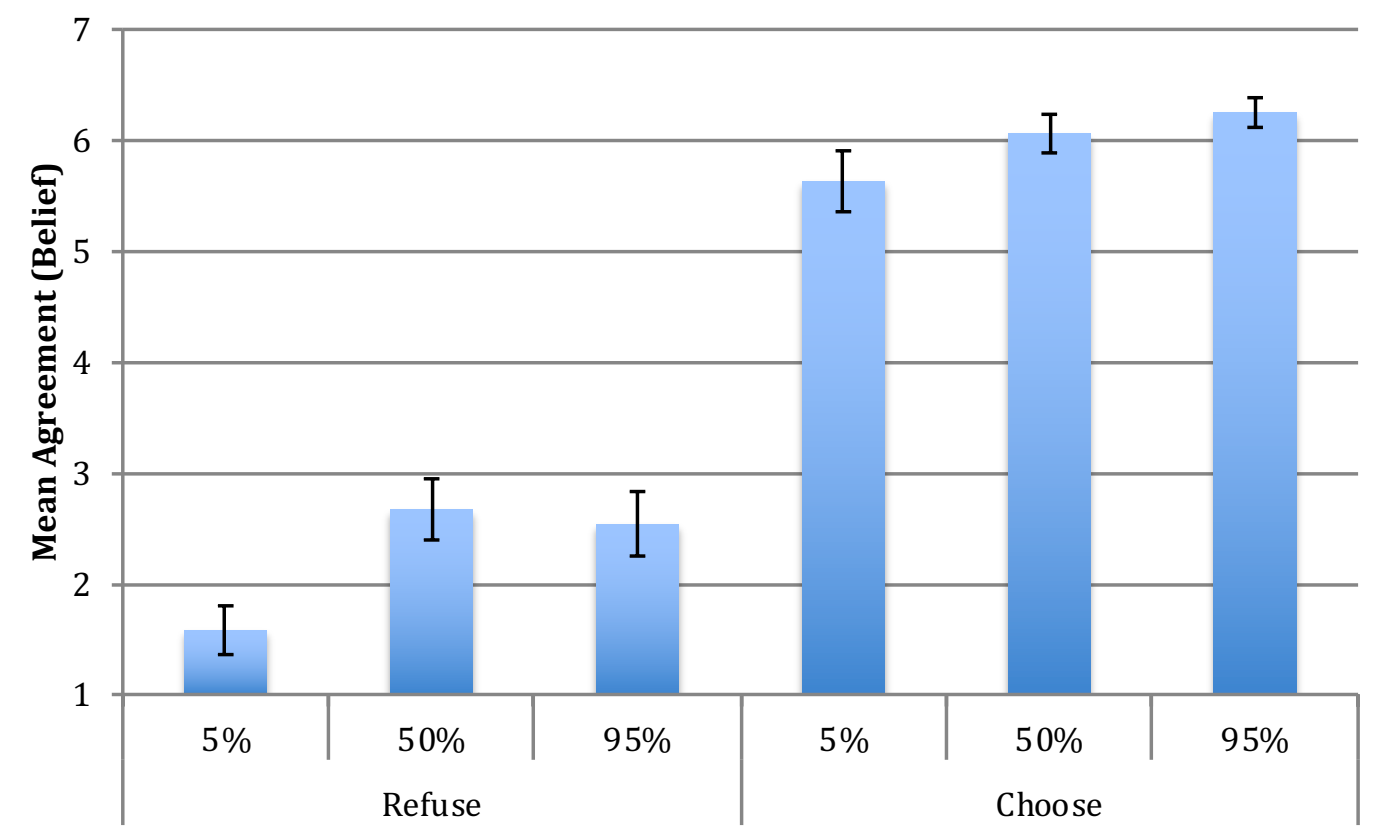

Fig. 3: From Turri, Rose, and Buckwalter (2017: Experiment 3). "Mean belief attribution to a protagonist who professed to either choose or refuse to believe a proposition that is either 5, 50, or $95 \%$ probable. All scales ran from 1 to 7 . Error bars \pm one standard error of the mean." Reprinted with permission.

Each of these effects has been replicated using different cover stories (see Turri, Rose, and Buckwalter 2017: Experiments 1B, 2, and 4). This research suggests that folk psychology regards many mental states, and most notably beliefs, as voluntary states.

\section{Dualistic Appraisals in Theory of Mind}

As a pervasive aspect of ordinary life, folk psychology and theory of mind play a central role in our determinations about what others believe and why they behave the way that they do. It is reasonable to suppose that we rely on the folk psychological system in both 
ordinary circumstances, as well as when professionals and lay people interact with patients with clinical and behavioral disorders. Though active in both circumstances, utilizing this system in different contexts may lead to different results. For instance, the same system may sometimes lead to negative outcomes when evaluating pathological cases by encouraging dualistic appraisals and biases to occur.

Two recently uncovered features of the folk-psychological system may be responsible for this result. The first aspect involves the doxastic conception of mental disorders. Evidence suggests that folk psychology strongly and unequivocally attributes belief to patients based on frequent assertion, such as in cases of monothematic delusion. The reason for this is that the assertions appear to be powerful cues for belief attribution in theory of mind even when behavioral integration and circumscription are absent. The folk psychological system also appears to trigger belief attribution in pathological and non-pathological cases alike, even though the nature of the assertions made between these two cases is presumably very different.

The second feature of the folk-psychological system involves voluntarism of mental states, and particularly, doxastic states. Research demonstrates that folk psychology strongly and unequivocally views belief as voluntary and perhaps as the most voluntary propositional attitude. Professed choice has an enormous impact on whether we judge that an agent believes or does not believe something. By comparison, level or strength of evidence for a belief played a much smaller role in what was viewed as believed. This research suggests that the control one has over one's beliefs may be judged similarly to the control one typically has over actions. 
Putting these features together, the result is a folk psychological schema that represents the contents of mental disorders as beliefs and fully embraces voluntarism about those beliefs. So, for example, when patients make assertions, the folk psychological system becomes activated, as it typically does. The system represents the content of these assertions as beliefs. The system also represents beliefs as highly voluntary mental states. Since beliefs are regarded as voluntary, the degree to which a patient is seen as holding a belief consistent with the content of a mental illness contributes to the perception disordered thinking is voluntary. Since the content of the belief flows directly from assertions characteristic of the mental disorder, this may even encourage the perception that the disorders themselves and resulting behaviors are voluntary.

If this description of the folk-psychological system is correct, then that system may indirectly encourage mind-brain dichotomies in our interpretations and evaluations of mental disorders. Of course, the evidence presented presently does not establish that professionals or laypeople necessarily think physical and mental disorders are made of biologically different components, but it does provide an explanation for why the tendency to engage in dualistic evaluations occurs. Physical pathologies are typically not considered voluntary. This, no doubt, partly has to do with the fact that much more information is available about physical ailments and the mechanisms that cause them. In the absence of this information in understanding mental disorders, we rely on the folk psychological system, instead. Neither do physical pathologies typically trigger activation of the folk psychological system of belief in the way that non-physical conditions do, 
which in turn decreases the likelihood that the relevant mental states are either regarded as voluntary or even attributed at all.

Viewing the contents of mental disorders, and perhaps even disorders themselves, as voluntary may exacerbate mental health stigmatization, including biased judgments of blame and punishment. Prior research has shown that judgments of blame and punishment are sensitive to perceived ability (for an overview see Buckwalter 2017). For example, researchers consistently find that blame for failing to complete tasks is less likely to be attributed when agents are perceived as unable to complete them (Buckwalter and Turri 2015). If ability is an important cue for ascriptions of blame, and the folk psychological system classifies mental disorders or their contents as within our ability to choose or refuse, this may also encourage the perception that mental illness is blameworthy or otherwise criticizable compared to physical illness or disability.

Given that the folk psychological system encourages dualistic evaluations of mental disorders, the natural next question is to ask what can be done about it: can understanding this schema help overcome dualistic responses in favor of a more scientific treatment of behavioral disorders? Though the most effective strategies for overcoming these negative effects will require much more research directly investigating the link between folk psychology and dualistic biases, the present results may have several implications.

First, the pervasive and persistent aspects of dualistic evaluations suggest that while clinicians may have developed more scientific frameworks for treating mental disorders, they have not transcended dualistic reactions to individual clinical scenarios. Moreover, if individual judgments are generated in part by the folk psychological system, 
it might be infeasible to expect clinicians or laypeople to ever fully transcend the tendency to draw mind-brain dichotomies. The very same system that we rely on when making theory of mind judgments can also leads to this result in pathological circumstances when evaluating mental disorders. Thus, rather than attempt to banish dualistic thinking from clinical practice entirely, it might be more practical to acknowledge that features of the folk psychological system are likely to continue to influence judgments, and subsequently take steps to track and mitigate them when they do arise.

Second, tracing the origins of dualistic biases to folk psychology suggests a straightforward strategy for beginning to mitigate them. The strategy is to disrupt activation of the folk psychological system in the context of evaluating mental disorders. Activation of the system can be discouraged at both the individual and theoretical level. On the individual level, the most straightforward way to accomplish this would be to withhold mental state attribution, of belief, for instance, on the basis of frequent assertion. When interacting with patients of mental disorders, there are pragmatic reasons to be hesitant to attribute or even to deny beliefs consistent with the content of mental disorders. In the same token, there are pragmatic reasons to reject the idea that the mental states that are formed are voluntary mental states. With respect to Capgras delusion, for example, we might be reticent to attribute belief of imposters to patients rather than a different sort of mental state, one that is not regularly thought to be voluntarily formed. Of course, these strategies do not provide a factual answer to the philosophical question of what individuals actually believe, but instead, are pragmatic suggestions for how changing practices of belief attribution could potentially reduce dualistic evaluations. 
Steps to discourage non-doxastic classification of the content of mental disorders can also be taken at the theoretical level, by reconsidering the way we define and diagnosis certain disorders. In the case of monothematic delusions, for instance, the DSM-V defines "delusions" as "false beliefs" (American Psychiatric Association 2013: 819). This definition of delusions is controversial in philosophy and has been criticized elsewhere (Coltheart 2007). However, present results suggest that the definition may also be criticizable for normative reasons. Defining delusions at the level of belief might accurately reflect folk psychological judgments of belief, but nonetheless have suboptimal effects on the level of patient treatment. Defining disorders such as monothematic delusion non-doxastically, or with sensitivity to this issue, may begin to help correct these effects and encourage a more scientific view of mental disorders.

Lastly, these results may also be useful for those who consider dualism to be a methodological virtue of modern clinical psychiatry. One common assumption is that mind-brain dichotomies in scientific treatment techniques persist despite conscious efforts to minimize them. However, some have explicitly embraced dualistic aspects of mental disorders for improving patient care. Perhaps the most extreme version of this tendency can be seen in practices of the popular Choice Theory (Glasser 1999), which emphasizes the internal control that a patient has over his or her behaviors and beliefs as opposed to external stimuli. Fostering a sense of control among patients in this way can often be adventitious in clinical settings, though is typically thought to encourage dualistic attitudes that are at odds with biological or brain-based approaches to psychiatric illness. The present results may suggest a mild compromise between these two approaches. Presumably, part of what fosters a sense of control comes from the 
voluntarist aspect of the folk psychological system in representing mental states. Thus, monitoring the conditions under which the folk psychological system becomes activated might channel feelings of control more productively. Making more fine-grained determinations of the mental states classified as a patient's beliefs may effectively foster involuntarism about those states associated with the content of the mental illness, and voluntarism about those states that are not associated.

\section{Conclusions}

Dualistic evaluations associated with mental disorders are common among health professionals and laypeople. This paper develops and supports a hypothesis tracing the persistence of these behaviors to the folk psychological system in theory of mind. Specifically, this may be explained, in part, by two features of the folk-psychological system involving the representation and evaluation of beliefs: the tendency to attribute beliefs and to treat beliefs as voluntary in ordinary judgment. Current evidence suggests that these features are central to the folk psychological system and may contribute to the perpetuation of mind-brain dichotomies in the evaluation of mental disorders.

Though the current hypothesis involves folk-psychological judgments of belief, the findings reviewed above may also be relevant to further philosophical projects attempted to characterize either the concept of belief or the physiological reality of belief. Theoretical debates about both doxastic voluntarism and doxasticism about delusion often appeal to evidence concerning social observation and ordinary judgment. In arguing against the claim that delusions are beliefs, for example, some theorists consider whether "having a belief just is a matter of living up to the folk-psychological expectations for 
believers of that content" (Tumulty 2012: 30). Similarly, philosophers have argued that voluntarism is false because the notion strikes us as "chokingly unswallowable" (Bennett 1990: 90; c.f. Turri, Rose, and Buckwalter 2017). The present results may undermine these arguments for what belief must be like that rely on or appeal to folk psychology, insofar as delusion and voluntarism do fit the folk psychology profile of belief. It is also possible that misdiagnosis of this profile in philosophy of mind has obscured the role of belief representation in dualistic appraisals common in psychiatry and social practice. Further research is needed to evaluate these claims.

Lastly, further work might profitably study the role of the folk psychological system in generating dualistic appraisals by expanding the theory to other mental states. It is likely that not all disorders are conceptualized doxastically nor their contents represented exclusively in terms of beliefs. For example, some disorders might also naturally lend themselves to attributions of affective states, such as fear or desire. Consistent with the present theory, prior research suggests that the folk-psychological system also represents these states as voluntary, broadly consistent with representations of belief (see, for example, Fig 2). However, further research is needed in philosophy and psychiatry to test this expanded hypothesis. Understanding the further role of folk psychology in these matters has the potential to reveal the underlying causes of lasting dualistic biases and begin to more effectively eliminate the negative effects associated with them.

Acknowledgements-Thanks to Carolyn Buckwalter, Richard Dub, Edouard Machery, Heidi Maibom, David Rose, Şerife Tekin, and John Turri for helpful feedback on prior 
drafts. This research was supported by the Social Sciences and Humanities Research Council of Canada.

\section{References}

Alston, William P. (1988), 'The deontological conception of epistemic justification', Philosophical Perspectives, 2, 257-99.

American Psychiatric Association (2013), Diagnostic and statistical manual of mental disorders (5th ed.) (Washington, D.C.: Author).

Andreasen, N. C. (1997), 'Linking mind and brain in the study of mental illnesses: a project for a scientific psychopathology', Science, 275 (5306), 1586-93.

Baron-Cohen, S. (1996), Mindblindness: An essay on autism and theory of mind (Cambridge, MA: MIT Press).

Bartsch, Karen and Wellman, Henry M (1995), Children talk about the mind (Oxford University Press on Demand).

Bayne, Tim (2010), 'Delusions as Doxastic States: Contexts, Compartments, and Commitments', Philosophy, Psychiatry, \& Psychology, 17 (4), 329-36.

Bennett, Jonathan (1990), 'Why is Belief Involuntary?', Analysis, 50 (2), 87-107.

Bortolotti, Lisa and Mameli, Matteo (2012), 'Self-Deception, Delusion and the Boundaries of Folk Psychology', Humana.mente, 20, 203-21.

Buckwalter, Wesley (2017), 'Ability, Responsibility, and Global Justice', Journal of Indian Council of Philosophical Research, 34 (3), 577-90.

Buckwalter, Wesley and Turri, John (2015), 'Inability and Obligation in Moral Judgment', PLOS One, 10 (8), https://doi.org/10.1371/journal.pone.0136589. 
Byrne, Peter (2001), 'Psychiatric stigma', The British Journal of Psychiatry, 178 (3), 28184.

Coltheart, M. (2007), 'Cognitive neuropsychiatry and delusional belief', Q J Exp Psychol (Hove), 60 (8), 1041-62.

Crandall, C. S. and Moriarty, D. (1995), 'Physical illness stigma and social rejection', BrJ Soc Psychol, 34 ( Pt 1), 67-83.

Descartes, Rene (1644/1985), 'The Principles of Philosophy', The Philosophical Writings of Descartes (Vol. 1) (Cambridge University Press).

Egan, Andrew (2009), 'Imagination, delusion, and self-deception', in T Bayne and J. Fernández (eds.), Delusions, self-deception, and affective influences on beliefformation (Hove, East Sussex: Psychology Press), 263-80.

Gabbard, Glen O. (2005), 'Mind, Brain, and Personality Disorders', American Journal of Psychiatry, 162 (4), 648-55.

Glasser, W (1999), Choice Theory: A New Psychology of Personal Freedom (India: Harper Collins).

Hinshaw, Stephen P. and Stier, Andrea (2008), 'Stigma as Related to Mental Disorders', Annual Review of Clinical Psychology, 4 (1), 367-93.

Hirstein, W. and Ramachandran, V. S. (1997), 'Capgras syndrome: a novel probe for understanding the neural representation of the identity and familiarity of persons', Proceedings of the Royal Society B: Biological Sciences, 264 (1380), 437-44.

Hobbes, T. (1641), 'Third set of objections, by a famous English philosopher', in R. Ariew and D. Cress (eds.), Meditations, objections, and replies (Indianapolis: Hackett), 100-14. 
James, William (1948), 'The will to believe', in A Castell (ed.), Essays in pragmatism (New York: Hafner Press), 88-109.

Kandel, E. R. (1998), 'A new intellectual framework for psychiatry', Am J Psychiatry, $155(4), 457-69$.

Kendler, K. S. (2001), 'A Psychiatric Dialogue on the Mind-Body Problem', American Journal of Psychiatry, 158 (7), 989-1000.

Kendler, K. S. (2005), 'Toward a philosophical structure for psychiatry', Am J Psychiatry, $162(3), 433-40$.

Kirmayer, Laurence J. (1988), 'Mind and Body as Metaphors: Hidden Values in Biomedicine', in Margaret Lock and Deborah Gordon (eds.), Biomedicine Examined (Dordrecht: Springer Netherlands), 57-93.

Leitan, Nuwan D. and Murray, Greg (2014), 'The mind-body relationship in psychotherapy: grounded cognition as an explanatory framework', Frontiers in Psychology, 5, 472.

Lim, Kim-Lian , Jacobs, Philip, and Dewa, Carolyn (2008), 'How Much Should We Spend on Mental Health?', Economic Reports (Institute of Health Economics, https://www.ihe.ca/publications/how-much-should-we-spend-on-mental-health-).

Luhrmann, T. M. (2000), Of 2 Minds: The growing disorder in American psychiatry (New York: Alfred A. Knopf).

Malle, B F (2003), 'The social cognition of intentional action', in P. W. Halligan, C. Bass, and D.. A. Oakley (eds.), Malingering and illness deception (Oxford: Oxford University Press), 83-92. 
Miresco, Marc J. and Kirmayer, Laurence J. (2006), 'The Persistence of Mind-Brain Dualism in Psychiatric Reasoning About Clinical Scenarios', American Journal of Psychiatry, 163 (5), 913-18.

Perner, Josef (1991), Understanding the representational mind (Cambridge, Mass: MIT Press).

Raese, Joachim (2014), 'The Pernicious Effect of Mind/Body Dualism in Psychiatry', $J$ Psychiatry, 18 (1000219), doi: 10.4172/Psychiatry.1000219.

Rose, David, Buckwalter, Wesley, and Turri, John (2014), 'When Words Speak Louder Than Actions: Delusion, Belief, and the Power of Assertion', Australasian Journal of Philosophy, 92 (4), 683-700.

Rose, David, et al. (2017), 'Behavioral Circumscription and the Folk Psychology of Belief: A Study in Ethno-Mentalizing', Thought: A Journal of Philosophy, 6 (3), 193-203.

Smetanin, P., Stiff, D., Briante, C., Adair, C.E., Ahmad, S., and Khan, M. T. (2011), 'The Life and Economic Impact of Major Mental Illnesses in Canada: 2011 to 2041', RiskAnalytica, on behalf of the Mental Health Commission of Canada 2011 (https://www.mentalhealthcommission.ca/sites/default/files/MHCC_Report_Base Case_FINAL_ENG_0_0.pdf).

Tumulty, Maura (2012), 'Delusions and Not-Quite-Beliefs', Neuroethics, 5 (1), 29-37.

Turri, John, Rose, David, and Buckwalter, Wesley (2017), 'Choosing and refusing: doxastic voluntarism and folk psychology', Philosophical Studies.

Weiner, B., Perry, R. P., and Magnusson, J. (1988), 'An attributional analysis of reactions to stigmas', J Pers Soc Psychol, 55 (5), 738-48. 
Wellman, Henry M (1990), The child's theory of mind (Cambridge, Mass: MIT Press).

Williams, Bernard (1973), 'Deciding to believe', Problems of the Self (Cambridge: Cambridge University Press), 136-51. 